\title{
Hospital case-volume and mortality after ovarian cancer surgery: a population-based retrospective cohort study
}

\section{Bo Rim Kim}

Seoul National University Hospital

Heewon Kim

Seoul National University Hospital

\section{Segyeong Joo}

Seoul National University Hospital

\section{Eun Jin Jang}

Andong National University

Junwoo Jo

Kyungpook National University

\section{Hannah Lee}

Seoul National University Hospital

Ho Geol Ryu ( $\nabla$ hogeol@gmail.com )

Seoul National University College of Medicine https://orcid.org/0000-0001-8952-6049

\section{Research}

Keywords: Ovarian cancer, Ovarian cancer surgery, Case-volume effect, In-hospital mortality, Long-term mortality

Posted Date: March 19th, 2021

DOI: https://doi.org/10.21203/rs.3.rs-92574/v2

License: (a) (1) This work is licensed under a Creative Commons Attribution 4.0 International License. Read Full License 


\section{Abstract \\ Background}

The goal of ovarian cancer surgery has recently shifted from optimal cytoreduction to more complete resection. This study attempted to reassess and update the association between surgical case-volume and both in-hospital and long-term mortality after ovarian cancer surgery using recent data.

\section{Methods}

Data from all adult patients who underwent ovarian cancer surgery in Korea between 2004 and 2017 were obtained from the database of Korean National Health Insurance Service. Hospitals were categorized by average annual number of surgeries considering overall distribution of case-volume. Postoperative in-hospital and 1, 3, 5-year mortality were analyzed using logistic regression.

\section{Results}

During the study period, 23,487 ovarian cancer surgeries were performed in 354 hospitals. High-, medium-, and low-volume centers were defined as > 100 cases/year, 30-100 cases/year, and $<30$ cases/year, respectively. In-hospital mortality was significantly higher in medium-volume (1.63\%; adjusted odds ratio, 2.28; confidence interval, $1.64-3.17 ; P<0.001)$ and low-volume (1.62\%; adjusted odds ratio; 2.12; confidence interval, $1.55-2.90 ; P<0.001)$ centers compared to high-volume centers $(1.13 \%)$. In addition, 1-year mortality after ovarian cancer surgery was $6.26 \%, 7.07 \%$, and $8.06 \%$ for high-volume, medium-volume, and low-volume centers, respectively, and the differences among the groups were significant. However, case-volume effect was not apparent in 3- and 5-year mortality after ovarian cancer surgery.

\section{Conclusions}

Case-volume effect was observed for in-hospital and 1-year mortality after ovarian cancer surgery while no clear association was found between the case-volume and 3- or 5-year mortality.

\section{Introduction}

Ovarian cancer is projected to be the fifth leading cause of cancer death in 2020 for women in the US [1], and accounts for nearly $4 \%$ of female cancer deaths in Korea [2]. Despite the recent decrease in the incidence and advances in treatment, the overall survival rate is still relatively low with a reported 5-year survival rate around $50 \%[3]$. 
The standard treatment for ovarian cancer has been surgical resection aiming for complete tumor removal followed by adjuvant chemotherapy. The goal of surgical resection has evolved from cytoreduction to complete resection in recent years [4,5]. Extensive and sophisticated surgery is often required for complete tumor resection as more than $70 \%$ of the patients are diagnosed in the advanced stage [6].

The impact of surgical volume on patient outcome has been widely studied for complex surgical procedures with significant postoperative morbidity such as major cancer resections, cardiovascular procedures, and solid organ transplantation [7-10]. The 0 has also been suggested for ovarian cancer surgery [11-14]. The change in the surgical paradigm towards a more complete resection of ovarian cancer calls for a reassessment of the case volume effect on both short- and long-term outcome after ovarian cancer surgery.

The purpose of this study was to analyze the association between the hospital case-volume of ovarian cancer surgery and in-hospital mortality along with 1,3,5-year mortality using the database from the Korean National Health Insurance Service (NHIS). It was hypothesized that higher surgical case-volume may be associated with lower in-hospital and long-term mortality after ovarian cancer surgery.

\section{Patients And Methods}

\section{Data source and study population}

The Korean NHIS governs the single payer universal health coverage system of Korea, the National Health Insurance (NHI) program and the Medical Aid program. Data obtained from the Korean NHIS database contains nearly all data of cancer surgeries that were performed for the Korean residents. ${ }^{17}$

Adult patients ( $\geq 19$ years) who underwent ovarian cancer surgery between 2004 and 2017 were identified by using the NHI procedure codes. Procedural code of extirpation of adnexal tumor for malignancy, staging, pelvic exenteration, and pelvic and para-aortic lymphadenectomy. Operations were categorized according to the extent of the surgery. Radical resection was defined as extirpation of the adnexal tumor with removal of parametrium or lymph nodes. Data from patients with malignant neoplasm of ovary, defined by the International Classification of Diseases, $10^{\text {th }}$ revision (ICD-10) diagnosis code of $\mathrm{C} 56$, were extracted.

\section{Variables and study endpoints}

Baseline characteristics including age, sex, and comorbidities such as hypertension, diabetes mellitus, coronary artery disease, chronic obstructive pulmonary disease, chronic liver disease, chronic kidney disease, and cerebrovascular disease were extracted from the database using ICD-10 diagnosis codes. Hypertension was defined as ICD codes for hypertension with anti-hypertensive drugs prescribed for more 
than 1 month. Diabetes mellitus was defined both ICD code for diabetes and insulin or oral hypoglycemic agents prescribed for more than 1 month. Adjuvant and neoadjuvant therapy data were collected using procedural codes. Data on in-hospital and 1, 3,5-year mortality were extracted as primary and secondary outcomes.

\section{Definition of case-volume}

The institutional case-volume was defined as the average annual number of ovarian cancer surgeries between 2004 and 2017. The cutoff values for categorizing centers according to case volume were not predetermined before data analysis. Predesignated factors to determine the cutoff values included overall distribution of case volume, comparable patient number in each group, and sufficient number of centers in each group for statistical comparison.

\section{Statistical analyses}

Continuous variables were presented as mean [standard deviation (SD)] or median [interquartile range (IQR)] and were analyzed using the $t$-test or Mann-Whitney U-test. Categorical variables were expressed as number (\%) and were analyzed using Pearson's chi-square test. In-hospital and 1, 3, 5 year-mortality after ovarian cancer surgery was evaluated according to the case-volume groups. Using multivariable logistic regression, potential risk factors were evaluated with adjustment for age, sex, adjuvant therapy, transfusion, and comorbidities. The results of the logistic regression were expressed as odds ratio (OR), 95\% confidence interval (Cl), and p-value.

All analyses were performed using SAS 9.4 (SAS Institute, Cary, NC), and $P<0.05$ was considered statistically significant.

\section{Ethical approval}

This population-based retrospective cohort study was determined to be exempt from review by the institutional review board of Seoul National University Hospital (E-1905-098-1034). Informed consent was also waived due to the retrospective nature of the study design and study feasibility.

\section{Results}

A total of 23,487 ovarian cancer patients underwent surgery in 354 hospitals in Korea between 2004 and 2017. Medical centers were categorized as low-volume centers (<30 cases/year), medium-volume centers (30-100 cases/year), or high-volume centers (>100 cases/year) according to the institutional casevolume. Patient and center characteristics are summarized in Table 1. More than one third of the ovarian 
cancer patients were operated in 5 high-volume centers of which median annual case volume was 118.21 (Table 1). Most of the patients were under 50 years old at the time of the operation and adjuvant chemotherapy was performed in almost all ovarian cancer patients (Table 1). More than half of the patients underwent radical extirpation of adnexal tumor with hysterectomy which includes bilateral salpingo-oophorectomy and removal of parametrium or lymph nodes (Table 1).

The overall in-hospital mortality after ovarian cancer surgery was $1.33 \%$ (312/23487). After adjusting for age, operation type, comorbidities, neoadjuvant chemotherapy, and transfusion, low-volume (adjusted OR, 2.12; $\mathrm{Cl}, 1.55-2.90$ ) and medium-volume (adjusted OR, 2.28; $\mathrm{Cl}, 1.64-3.17)$ centers showed significantly higher in-hospital mortality compared to high-volume centers (Table 2). Older age, hypertension, diabetes mellitus, coronary artery disease, and perioperative transfusion were also identified as risk factors for inhospital mortality (Table 2).

Table 3 showed the result of logistic regression for long-term mortality after ovarian cancer surgery. The overall all-cause 1, 3, and 5-year mortality after ovarian cancer surgery were 7.18\% (1665/23175), 23.04\% (4330/18790), and 33.91\% (5094/15023), respectively. Patients who received the operation in highvolume centers showed significantly lower 1 -year mortality compared to patients who received care in medium and low volume centers. The case volume effect was not identifiable at 3 and 5 years after surgery (Table 3). Older age and perioperative transfusion were consistent risk factor for mortality at all time points. Patients who received neoadjuvant chemotherapy in addition to adjuvant chemotherapy showed significantly higher long-term mortality (Table 3).

\section{Discussion}

In this study, the institutional case-volume of ovarian cancer surgery was identified as an independent risk factor for in-hospital or 1-year mortality. No definite correlation was found between case volume and 3-year or 5-year mortality.

The standard treatment for ovarian cancer has been surgery with an aim for complete tumor removal followed by adjuvant chemotherapy. The use of neoadjuvant chemotherapy or radiotherapy is limited to specific circumstances and require more evidence [15-16]. Ovarian cancer can be considered as a highrisk surgery as more than $70 \%$ of the patients are diagnosed in the advanced stage with cancer involvement of the peritoneal cavity and adjacent organs $[6,17]$. Extensive resections including salpingooophorectomy, hysterectomy, omentectomy, and occasionally resection of the bowel, bladder, liver, spleen, diaphragm or other organs are required to achieve maximal cytoreduction which is associated with longterm prognosis $[18,19]$. A relatively small prospective observational study of 275 patients in Finland demonstrated that higher hospital operative volume (>20 cases/year) was associated with more optimal cytoreduction and a significant prognostic factor for 5-year survival [13]. Recently, complete resection of all macroscopic tumor was emphasized as the cornerstone for ovarian cancer treatment as residual tumor of even less than $1 \mathrm{~cm}$ in diameter was associated with worse prognosis compared to complete resection $[5,20]$. 
Previous studies have reported conflicting results regarding the association between the surgical case volume of ovarian cancer and postoperative outcomes [11-14]. An analysis of 100,725 patients using the National Cancer Database of the US, both 2- and 5-year survival were lower in low-volume centers (1-2 cases/year) compared to high-volume centers ( $\geq 20$ cases/year) after categorizing the hospitals into quintiles according to annual case volume $(64.4 \%$ vs. $77.4 \%$ for 2 -year survival, $P<0.001 ; 39.3 \%$ vs. $51.0 \%$ for 5 -year survival, $P<0.001$ ] [21]. Another report that investigated advanced-stage epithelial ovarian cancer showed that hospital volume $\geq 21$ cases/year was a strong predictor of 5-year overall survival after analyzing 45,929 patients from the National Cancer Database of the US [12]. To the contrary, another study that evaluated 2,952 patients aged 65 years or older did not show any association between hospital surgical volume and 60-day mortality or overall survival when hospitals were grouped into tertiles based on hospital surgical volume (cutoff value of 13 and 29 cases/year) between 1992 to 1999 [14]. While prior studies defined high-volume center as an annual volume 20 or more cases per year, the determined cutoff value in our study was 30 and 100 cases per year for medium- and high-volume center respectively after visual inspection of the distribution of the annual case volume and number of patients. It seems likely that there may be another cutoff past 20-29 cases per year, beyond which patient outcome may improve, yet again.

Ovarian cancer surgery is often accompanied by significant postoperative morbidity. According to a previous analysis of 28,651 women who underwent ovarian cancer surgery, the complication rate ranged from $17.1 \%$ in patients under 50 years to $31.5 \%$ of in patients over 80 years of age [22]. Another study reported that severe postoperative complications within 90 days after primary debulking surgery for advanced epithelial ovarian cancer showed that events requiring invasive interventions or re-operation, organ systems failure, or postoperative death occurred in $22.3 \%(138 / 620)$ of patients [23]. In another study that classified hospitals into tertiles based on case volume, failure to rescue rates (defined as the mortality following a major complication), were higher in patients treated at low-volume hospitals compared to patients treated in high-volume hospitals ( $8.0 \%$ vs. $4.9 \%, \mathrm{P}<0.001)$ [24]. In this regard, accumulated experience in coping with postoperative complications may play an important role in casevolume effect.

Unlike previous reports, the surgical case-volume effect was not demonstrated at 3 or 5 years after surgery in the present study $[12,21]$. Potential mechanisms behind the dilution of case volume effect over time may include the relatively high level of access to care. As a small country with complex transportation infrastructure, large hospitals which are high volume centers can be accessed from anywhere in the country within 3-4 hours. It is also relatively easy to seek care in high volume centers as the requirements are easy to meet. Considering that the stage of the ovarian cancer at the time of surgery was not available in the data, and therefore not adjusted for, concentration of patients in advanced stages in high volume centers may have contributed to the dilution of the case volume effect.

Case-volume effect on patient outcome has been demonstrated mainly in high-risk procedures such as major cancer resections, cardiovascular procedures, and heart transplantation [7-10] while relatively simple surgical procedures such as laparoscopic cholecystectomy showed no significant case-volume 
effect [25, 26]. Experienced surgical teams, nurses, and anesthesiologists are more likely to be prepared to optimally manage anticipated and unanticipated complications that may occur during high-risk surgical procedures. With regards to ovarian cancer surgery, collaboration with other specialists such as general surgeons, urologic surgeons, or thoracic surgeons are often required for optimal treatment. In this respect, comprehensive perioperative care by multidisciplinary team consisting of sufficient and skilled medical personnel as well as accumulated experience of individual surgeons may explain, to some extent, the case-volume effect in high-volume centers. The suggested amount of experience that may lead to the best patient outcome in this study was 100 cases of ovarian cancer surgery per year.

Several limitations should be considered when interpreting the result of this study. First, this study was a retrospective analysis of an administrative database. Therefore, the results may be subject to biases and limitations of retrospective studies and database not designed/collected for research. However, the database used in our study contains data from all 23,487 patients who received surgery for ovarian cancer in Korea during the study period, which may compensate for the shortcomings stated above and provide a relatively strong explanatory power. Second, clinical information such as staging, histologic diagnosis, or laboratory findings were not available. Although these clinical variables are likely to influence patient treatment and subsequent outcomes, individual clinical data could not be obtained due to the nature of the administrative database. Potential confounders that could be identified such as operation type, adjuvant therapy, and comorbidities were adjusted for. Third, the determined cutoff values of volume criteria were not previously validated. However, cutoff criteria for case volume may be bound to differ depending on the healthcare system, geographical circumstances, and the type of surgical procedure. Therefore, cutoff values for determining case volume effect may not need external validation as it would not be feasible to apply cutoff values determined from studies performed in different settings and time.

\section{Conclusion}

In conclusion, low-volume hospitals showed significantly higher in-hospital and 1-year mortality after ovarian cancer surgery. No clear association was found between the case-volume and 3- or 5-year mortality.

\section{References}

1. Siegel RL, Miller KD, Jemal A. Cancer statistics, 2020. CA Cancer J Clin. 2020;70(1):7-30. doi:10.3322/caac.21590.

2. Jung K-W, Won Y-J, Hong S, et al. Prediction of Cancer Incidence and Mortality in Korea, 2020. Cancer Res Treat. 2020;52(2):351-8. doi:10.4143/crt.2020.203.

3. Torre LA, Trabert B, DeSantis CE, et al. Ovarian cancer statistics, 2018. CA Cancer J Clin. 2018;68(4):284-96. doi:10.3322/caac.21456. 
4. Hoskins WJ, McGuire WP, Brady MF, et al. (1994) The effect of diameter of largest residual disease on survival after primary cytoreductive surgery in patients with suboptimal residual epithelial ovarian carcinoma. Am J Obstet Gynecol 170 (4):974-979; discussion 979-980. doi:10.1016/s00029378(94)70090-7.

5. du Bois A, Reuss A, Pujade-Lauraine E, et al. Role of surgical outcome as prognostic factor in advanced epithelial ovarian cancer: a combined exploratory analysis of 3 prospectively randomized phase 3 multicenter trials: by the Arbeitsgemeinschaft Gynaekologische Onkologie Studiengruppe Ovarialkarzinom (AGO-OVAR) and the Groupe d'Investigateurs Nationaux Pour les Etudes des Cancers de l'Ovaire (GINECO). Cancer. 2009;115(6):1234-44. doi:10.1002/cncr.24149.

6. Heintz A, Odicino F, Maisonneuve P, et al. Carcinoma of the Ovary. Int J Gynaecol Obstet. 2006;95(Suppl 1):161-s192. doi:10.1016/s0020-7292(06)60033-7.

7. Begg CB, Cramer LD, Hoskins WJ, et al. Impact of hospital volume on operative mortality for major cancer surgery. JAMA. 1998;280(20):1747-51. doi:10.1001/jama.280.20.1747.

8. Birkmeyer JD, Siewers AE, Finlayson EV, et al. Hospital volume and surgical mortality in the United States. N Engl J Med. 2002;346(15):1128-37. doi:10.1056/NEJMsa012337.

9. Hata T, Motoi F, Ishida M, et al. Effect of Hospital Volume on Surgical Outcomes After Pancreaticoduodenectomy: A Systematic Review and Meta-analysis. Ann Surg. 2016;263(4):664-72. doi:10.1097/sla.0000000000001437.

10. Nam K, Jang EJ, Kim GH, et al. Institutional Case-Volume and Mortality After Heart Transplantation. Int Heart J. 2019;60(3):695-700. doi:10.1536/ihj.18-428.

11. Bristow RE, Zahurak ML, Diaz-Montes TP, et al. Impact of surgeon and hospital ovarian cancer surgical case volume on in-hospital mortality and related short-term outcomes. Gynecol Oncol. 2009;115(3):334-8. doi:10.1016/j.ygyno.2009.08.025.

12. Bristow RE, Palis BE, Chi DS, et al. The National Cancer Database report on advanced-stage epithelial ovarian cancer: impact of hospital surgical case volume on overall survival and surgical treatment paradigm. Gynecol Oncol. 2010;118(3):262-7. doi:10.1016/j.ygyno.2010.05.025.

13. Kumpulainen $S$, Sankila R, Leminen A, et al. The effect of hospital operative volume, residual tumor and first-line chemotherapy on survival of ovarian cancer - a prospective nation-wide study in Finland. Gynecol Oncol. 2009;115(2):199-203. doi:10.1016/j.ygyno.2009.07.011.

14. Schrag D, Earle C, Xu F, et al. Associations between hospital and surgeon procedure volumes and patient outcomes after ovarian cancer resection. J Natl Cancer Inst. 2006;98(3):163-71. doi:10.1093/jnci/djj018.

15. Elies A, Riviere S, Pouget N, et al. The role of neoadjuvant chemotherapy in ovarian cancer. Expert Rev Anticancer Ther. 2018;18(6):555-66. doi:10.1080/14737140.2018.1458614.

16. Fields EC, McGuire WP, Lin L, et al. Radiation Treatment in Women with Ovarian Cancer: Past, Present, and Future. Front Oncol. 2017;7:177-7. doi:10.3389/fonc.2017.00177.

17. Clarke-Pearson DL. Clinical practice. Screening for ovarian cancer. N Engl J Med. 2009;361(2):170-7. doi:10.1056/NEJMcp0901926. 
18. Eisenkop SM, Friedman RL, Wang HJ. Complete cytoreductive surgery is feasible and maximizes survival in patients with advanced epithelial ovarian cancer: a prospective study. Gynecol Oncol. 1998;69(2):103-8. doi:10.1006/gyno.1998.4955.

19. Aletti GD, Dowdy SC, Gostout BS, et al. Aggressive surgical effort and improved survival in advancedstage ovarian cancer. Obstet Gynecol. 2006;107(1):77-85. doi:10.1097/01.AOG.0000192407.04428.bb.

20. Colombo N, Sessa C, du Bois A, et al. (2019) ESMO-ESGO consensus conference recommendations on ovarian cancer: pathology and molecular biology, early and advanced stages, borderline tumours and recurrent diseaset. Ann Oncol 30 (5):672-705. doi:10.1093/annonc/mdz062.

21. Wright JD, Chen L, Hou JY, et al. Association of Hospital Volume and Quality of Care With Survival for Ovarian Cancer. Obstet Gynecol. 2017;130(3):545-53. doi:10.1097/aog.0000000000002164.

22. Wright JD, Lewin SN, Deutsch I, et al. Defining the limits of radical cytoreductive surgery for ovarian cancer. Gynecol Oncol. 2011;123(3):467-73. doi:10.1016/j.ygyno.2011.08.027.

23. Kumar A, Janco JM, Mariani A, et al. Risk-prediction model of severe postoperative complications after primary debulking surgery for advanced ovarian cancer. Gynecol Oncol. 2016;140(1):15-21. doi:10.1016/j.ygyno.2015.10.025.

24. Wright JD, Herzog TJ, Siddiq Z, et al. Failure to rescue as a source of variation in hospital mortality for ovarian cancer. J Clin Oncol. 2012;30(32):3976-82. doi:10.1200/jco.2012.43.2906.

25. Murphy MM, Ng SC, Simons JP, et al. Predictors of major complications after laparoscopic cholecystectomy: surgeon, hospital, or patient? J Am Coll Surg. 2010;211(1):73-80. doi:10.1016/j.jamcollsurg.2010.02.050.

26. Donkervoort SC, Dijksman LM, Versluis PG, et al. Surgeon's volume is not associated with complication outcome after laparoscopic cholecystectomy. Dig Dis Sci. 2014;59(1):39-45. doi:10.1007/s10620-013-2885-5.

\section{Declarations}

Ethics approval and consent to participate: Ethics approval was waived by the Seoul National University Hospital IRB due to anonymity of the data.

Consent for publication: Not applicable

Availability of data and materials: The data that support the findings of this study are available from the Korean National Health Insurance Service database, but restrictions apply to the availability of these data, which were used under license for the current study, and so are not publicly available. Data are however available from the authors upon reasonable request and with permission of the Korean National Health Insurance Service.

Competing interests: The authors declare that they have no competing interests.

Funding information: This work was supported by Research Resettlement Fund for the new faculty of Seoul National University (800-20180443). 
Authors' contributions

Conception and design: all authors.

Data acquisition: H.K., E.J.J., J.J.

Data analysis: E.J.J., J.J.

Manuscript drafting: B.R.K., H.K., H.L., H.G.R

Manuscript revision: B.R.K., S.J., H.L. H.G.R.

Final approval: all authors.

Acknowledgements: None

\section{Tables}

Table 1. Patient and center characteristics 


\begin{tabular}{|c|c|c|c|c|c|}
\hline & Total & $\begin{array}{l}\text { Low-volume } \\
\qquad(<30 \\
\text { cases/year })\end{array}$ & $\begin{array}{c}\text { Medium-volume } \\
(30-100 \\
\text { cases/year) } \\
\end{array}$ & $\begin{array}{l}\text { High-volume } \\
\qquad(>100 \\
\text { cases/year })\end{array}$ & $P$ \\
\hline Number of centers & 354 & 336 & 13 & 5 & \\
\hline Number of patients & 23487 & 9278 & 6253 & 7956 & \\
\hline \multirow[t]{2}{*}{ Annual case volume } & 0.33 & 0.29 & 42.43 & 118.21 & $<0.001$ \\
\hline & {$[0.14,3.43]$} & {$[0.14,1.50]$} & {$[37.79,57.07]$} & {$[116.36,178.93]$} & \\
\hline Age & $52.14(13.56)$ & $52.51(14.12)$ & $51.33(13.83)$ & $52.33(12.64)$ & $<0.001$ \\
\hline $19-60$ & $\begin{array}{c}16685 \\
(71.04 \%)\end{array}$ & $6458(69.61 \%)$ & $4489(71.79 \%)$ & $5738(72.12 \%)$ & $<0.001$ \\
\hline $61-70$ & $4244(18.07 \%)$ & $1629(17.56 \%)$ & $1141(18.25 \%)$ & $1474(18.53 \%)$ & \\
\hline $71-80$ & $2177(9.27 \%)$ & $986(10.63 \%)$ & $535(8.56 \%)$ & $656(8.25 \%)$ & \\
\hline$\geq 81$ & $381(1.62 \%)$ & $205(2.21 \%)$ & $88(1.41 \%)$ & $88(1.11 \%)$ & \\
\hline Operation type & & & & & $<0.001$ \\
\hline $\begin{array}{l}\text { Radical resection without } \\
\text { hysterectomy }\end{array}$ & $3059(13.02 \%)$ & $1258(13.56 \%)$ & $879(14.06 \%)$ & $922(11.59 \%)$ & \\
\hline Radical resection with hysterectomy & $\begin{array}{c}13475 \\
(57.37 \%)\end{array}$ & $4432(47.77 \%)$ & $3547(56.72 \%)$ & $5496(69.08 \%)$ & \\
\hline $\begin{array}{l}\text { Simple resection without } \\
\text { hysterectomy }\end{array}$ & $3307(14.08 \%)$ & $1691(18.23 \%)$ & $825(13.19 \%)$ & 791 (9.94\%) & \\
\hline Simple resection with hysterectomy & $2266(9.65 \%)$ & $1354(14.59 \%)$ & $512(8.19 \%)$ & $400(5.03 \%)$ & \\
\hline Others & $1380(5.88 \%)$ & $543(5.85 \%)$ & $490(7.84 \%)$ & $347(4.36 \%)$ & \\
\hline \multicolumn{6}{|l|}{ Comorbidities } \\
\hline Hypertension & $5830(24.82 \%)$ & $2467(26.59 \%)$ & $1510(24.15 \%)$ & $1853(23.29 \%)$ & $<0.001$ \\
\hline Diabetes mellitus & $3627(15.44 \%)$ & $1388(14.96 \%)$ & $936(14.97 \%)$ & $1303(16.38 \%)$ & 0.018 \\
\hline Coronary artery disease & $1421(6.05 \%)$ & $545(5.87 \%)$ & $397(6.35 \%)$ & $479(6.02 \%)$ & 0.472 \\
\hline $\begin{array}{l}\text { Chronic obstructive pulmonary } \\
\text { disease }\end{array}$ & $560(2.38 \%)$ & $151(1.63 \%)$ & $105(1.68 \%)$ & $304(3.82 \%)$ & $<0.001$ \\
\hline Chronic liver disease & $6080(25.89 \%)$ & $2223(23.96 \%)$ & $1824(29.17 \%)$ & $2033(25.55 \%)$ & $<0.001$ \\
\hline Chronic kidney disease & $162(0.69 \%)$ & $78(0.84 \%)$ & $39(0.62 \%)$ & $45(0.57 \%)$ & 0.072 \\
\hline Cerebrovascular disease & $929(3.96 \%)$ & $399(4.30 \%)$ & $224(3.58 \%)$ & $306(3.85 \%)$ & 0.066 \\
\hline \multicolumn{6}{|l|}{ Adjuvant therapy } \\
\hline Neoadjuvant chemotherapy & $\begin{array}{c}11116 \\
(47.33 \%)\end{array}$ & $3758(40.50 \%)$ & $2593(41.47 \%)$ & $4765(59.89 \%)$ & $<0.001$ \\
\hline Adjuvant chemotherapy & $\begin{array}{c}23441 \\
(99.80 \%)\end{array}$ & $9252(99.72 \%)$ & $6237(99.74 \%)$ & 7952 (99.95\%) & 0.001 \\
\hline Neoadjuvant radiotherapy & $51(0.22 \%)$ & $15(0.16 \%)$ & $16(0.26 \%)$ & $20(0.25 \%)$ & 0.336 \\
\hline Adjuvant radiotherapy & $372(1.58 \%)$ & $156(1.68 \%)$ & $109(1.74 \%)$ & $107(1.34 \%)$ & 0.106 \\
\hline Chemoradiotherapy & $417(1.78 \%)$ & $170(1.83 \%)$ & $124(1.98 \%)$ & $123(1.55 \%)$ & 0.128 \\
\hline Transfusion required & 12614 & $4619(49.78 \%)$ & $3336(53.35 \%)$ & $4659(58.56 \%)$ & $<0.001$ \\
\hline
\end{tabular}


Values are expressed as mean (standard deviation), median [interquartile range] or $\mathrm{n}(\%)$.

Table 2. Logistic regression analysis for in-hospital mortality after ovarian cancer surgery 


\begin{tabular}{|c|c|c|c|c|c|}
\hline & \multirow{2}{*}{$\begin{array}{c}\text { In-hospital mortality } \\
{[\mathrm{n} / \mathrm{N}(\%)]}\end{array}$} & \multicolumn{2}{|c|}{ Unadjusted } & \multicolumn{2}{|c|}{ Adjusted } \\
\hline & & OR $(95 \% \mathrm{Cl})$ & $P$ & OR $(95 \% \mathrm{Cl})$ & $P$ \\
\hline j0 & 134/16685 (0.80\%) & 1 & & 1 & \\
\hline 70 & $77 / 4244(1.81 \%)$ & $2.28(1.72-3.03)$ & $<0.001$ & $1.53(1.13-2.07)$ & 0.006 \\
\hline \multirow[t]{2}{*}{30} & $89 / 2177(4.09 \%)$ & $5.26(4.01-6.91)$ & $<0.001$ & $2.71(1.98-3.71)$ & $<0.001$ \\
\hline & 12/381 (3.15\%) & $4.02(2.21-7.32)$ & $<0.001$ & $1.99(1.05-3.75)$ & 0.034 \\
\hline \multicolumn{6}{|l|}{ jidities } \\
\hline rtension & $149 / 5830(2.56 \%)$ & $2.81(2.25-3.52)$ & $<0.001$ & $1.40(1.07-1.85)$ & 0.016 \\
\hline etes mellitus & $96 / 3627(2.65 \%)$ & $2.47(1.94-3.15)$ & $<0.001$ & $1.35(1.03-1.78)$ & 0.031 \\
\hline nary artery disease & 48/1421 (3.38\%) & $2.89(2.11-3.95)$ & $<0.001$ & $1.41(1.00-1.99)$ & 0.050 \\
\hline nic obstructive pulmonary disease & $12 / 560(2.14 \%)$ & $1.65(0.92-2.96)$ & 0.092 & $1.07(0.59-1.97)$ & 0.819 \\
\hline nic liver disease & $109 / 6080(1.79 \%)$ & $1.55(1.22-1.96)$ & $<0.001$ & $1.10(0.86-1.41)$ & 0.439 \\
\hline nic kidney disease & 9/162 (5.56\%) & $4.47(2.26-8.84)$ & $<0.001$ & $1.71(0.84-3.48)$ & 0.139 \\
\hline brovascular disease & $25 / 929(2.69 \%)$ & $2.15(1.42-3.25)$ & $<0.001$ & $0.92(0.59-1.43)$ & 0.703 \\
\hline \multicolumn{6}{|l|}{ on type } \\
\hline zal resection without hysterectomy & $32 / 3059(1.05 \%)$ & 1 & & 1 & \\
\hline zal resection with hysterectomy & 150/13475 (1.11\%) & $1.06(0.73-1.56)$ & 0.748 & $0.81(0.55-1.20)$ & 0.300 \\
\hline le resection without hysterectomy & $55 / 3307(1.66 \%)$ & $1.60(1.03-2.48)$ & 0.036 & $2.23(1.42-3.49)$ & 0.001 \\
\hline le resection with hysterectomy & $43 / 2266(1.90 \%)$ & $1.83(1.15-2.90)$ & 0.010 & $1.57(0.98-2.52)$ & 0.060 \\
\hline rs & $32 / 1380(2.32 \%)$ & $2.25(1.37-3.68)$ & 0.001 & $1.94(1.17-3.21)$ & 0.011 \\
\hline \multicolumn{6}{|l|}{ uvant chemotherapy } \\
\hline & 140/12371 (1.13\%) & 1 & & 1 & \\
\hline & 172/11116 (1.55\%) & $1.37(1.1-1.72)$ & 0.006 & $1.12(0.88-1.42)$ & 0.363 \\
\hline \multicolumn{6}{|l|}{ ısion } \\
\hline & 18/10873 (0.17\%) & 1 & & 1 & \\
\hline & 294/12614 (2.33\%) & 14.39 (8.94-23.18) & $<0.001$ & $15.64(9.64-25.39)$ & $<0.001$ \\
\hline \multicolumn{6}{|l|}{ Jlume } \\
\hline -volume centers & $60 / 7956(0.75 \%)$ & 1 & & 1 & \\
\hline \multicolumn{6}{|l|}{0 cases/year) } \\
\hline ium-volume centers & $102 / 6253(1.63 \%)$ & $2.18(1.58-3.01)$ & $<0.001$ & $2.28(1.64-3.17)$ & $<0.001$ \\
\hline \multicolumn{6}{|l|}{ I00 cases/year) } \\
\hline -volume centers & $150 / 9278$ (1.62\%) & $2.16(1.60-2.92)$ & $<0.001$ & $2.12(1.55-2.90)$ & $<0.001$ \\
\hline cases/year) & & & & & \\
\hline
\end{tabular}

$\mathrm{OR}$, odds ratio; $\mathrm{Cl}$, confidence interval

Table 3. Multivariable logistic regression analysis for 1, 3, 5-year mortality after ovarian cancer surgery 


\begin{tabular}{|c|c|c|c|c|c|c|c|c|c|}
\hline & \multicolumn{3}{|c|}{ 1-year mortality } & \multicolumn{2}{|c|}{ 3-year mortality } & \multicolumn{4}{|c|}{ 5-year mortality } \\
\hline & $\mathrm{n} / \mathrm{N}(\%)$ & $\begin{array}{l}\text { OR }(95 \% \\
\quad \mathrm{Cl})\end{array}$ & $P$ & $\mathrm{n} / \mathrm{N}(\%)$ & $\begin{array}{c}\text { OR } \\
(95 \% \\
\mathrm{Cl})\end{array}$ & $P$ & $\mathrm{n} / \mathrm{N}(\%)$ & $\begin{array}{c}\text { OR } \\
(95 \% \\
\mathrm{Cl})\end{array}$ & $P$ \\
\hline \multicolumn{10}{|l|}{ Age } \\
\hline $19-60$ & $\begin{array}{c}862 / 16551 \\
(5.21 \%)\end{array}$ & 1 & & $\begin{array}{c}2562 / 13584 \\
(18.86 \%)\end{array}$ & 1 & & $\begin{array}{c}3132 / 10978 \\
(28.53 \%)\end{array}$ & 1 & \\
\hline $61-70$ & $\begin{array}{c}357 / 4167 \\
(8.57 \%)\end{array}$ & $\begin{array}{c}1.39 \\
(1.21 \\
1.59)\end{array}$ & $<0.001$ & $\begin{array}{l}950 / 3307 \\
(28.73 \%)\end{array}$ & $\begin{array}{c}1.44 \\
(1.31 \\
1.58)\end{array}$ & $<0.001$ & $\begin{array}{c}1134 / 2583 \\
(43.90 \%)\end{array}$ & $\begin{array}{r}1.60 \\
(1.45 \\
1.76)\end{array}$ & $<0.001$ \\
\hline $71-80$ & $\begin{array}{l}357 / 2088 \\
(17.10 \%)\end{array}$ & $\begin{array}{c}2.69 \\
(2.31 \\
3.13)\end{array}$ & $<0.001$ & $\begin{array}{l}697 / 1627 \\
(42.84 \%)\end{array}$ & $\begin{array}{r}2.60 \\
(2.30 \\
2.93)\end{array}$ & $<0.001$ & $\begin{array}{l}713 / 1254 \\
(56.86 \%)\end{array}$ & $\begin{array}{r}2.70 \\
(2.36 \\
3.09)\end{array}$ & $<0.001$ \\
\hline$\geq 81$ & $\begin{array}{c}89 / 369 \\
(24.12 \%)\end{array}$ & $\begin{array}{c}4.11 \\
(3.15 \\
5.37)\end{array}$ & $<0.001$ & $\begin{array}{l}121 / 272 \\
(44.49 \%)\end{array}$ & $\begin{array}{c}3.07 \\
(2.37 \\
3.98)\end{array}$ & $<0.001$ & $\begin{array}{l}115 / 208 \\
(55.29 \%)\end{array}$ & $\begin{array}{c}2.88 \\
(2.14 \\
3.87)\end{array}$ & $<0.001$ \\
\hline \multicolumn{10}{|l|}{ Comorbidities } \\
\hline Hypertension & $\begin{array}{l}633 / 5681 \\
(11.14 \%)\end{array}$ & $\begin{array}{c}1.17 \\
(1.03, \\
1.33)\end{array}$ & 0.018 & $\begin{array}{c}1367 / 4509 \\
(30.32 \%)\end{array}$ & $\begin{array}{c}1.07 \\
(0.98 \\
1.17)\end{array}$ & 0.154 & $\begin{array}{c}1533 / 3545 \\
(43.24 \%)\end{array}$ & $\begin{array}{r}1.05 \\
(0.95 \\
1.16)\end{array}$ & 0.323 \\
\hline Diabetes mellitus & $\begin{array}{l}390 / 3531 \\
(11.05 \%)\end{array}$ & $\begin{array}{r}1.15 \\
(1.00 \\
1.31)\end{array}$ & 0.055 & $\begin{array}{l}845 / 2764 \\
(30.57 \%)\end{array}$ & $\begin{array}{c}1.09 \\
(0.98 \\
1.21)\end{array}$ & 0.099 & $\begin{array}{l}948 / 2139 \\
(44.32 \%)\end{array}$ & $\begin{array}{c}1.13 \\
(1.02 \\
1.26)\end{array}$ & 0.025 \\
\hline $\begin{array}{l}\text { Coronary artery } \\
\text { disease }\end{array}$ & $\begin{array}{l}163 / 1373 \\
(11.87 \%)\end{array}$ & $\begin{array}{r}1.02 \\
(0.85 \\
1.24)\end{array}$ & 0.822 & $\begin{array}{l}351 / 1119 \\
(31.37 \%)\end{array}$ & $\begin{array}{c}1.01 \\
(0.87 \\
1.17)\end{array}$ & 0.879 & $\begin{array}{l}419 / 926 \\
(45.25 \%)\end{array}$ & $\begin{array}{r}1.04 \\
(0.90 \\
1.22)\end{array}$ & 0.576 \\
\hline $\begin{array}{l}\text { Chronic obstructive } \\
\text { pulmonary disease }\end{array}$ & $\begin{array}{c}57 / 548 \\
(10.40 \%)\end{array}$ & $\begin{array}{r}1.05 \\
(0.78 \\
1.40)\end{array}$ & 0.766 & $\begin{array}{l}137 / 507 \\
(27.02 \%)\end{array}$ & $\begin{array}{c}0.86 \\
(0.70 \\
1.07)\end{array}$ & 0.167 & $\begin{array}{l}185 / 463 \\
(39.96 \%)\end{array}$ & $\begin{array}{c}0.87 \\
(0.70 \\
1.06)\end{array}$ & 0.169 \\
\hline Chronic liver disease & $\begin{array}{c}532 / 5971 \\
(8.91 \%)\end{array}$ & $\begin{array}{c}1.11 \\
(0.99 \\
1.25)\end{array}$ & 0.066 & $\begin{array}{c}1369 / 4699 \\
(29.13 \%)\end{array}$ & $\begin{array}{r}1.30 \\
(1.20 \\
1.41)\end{array}$ & $<0.001$ & $\begin{array}{c}1544 / 3655 \\
(42.24 \%)\end{array}$ & $\begin{array}{c}1.34 \\
(1.24 \\
1.46)\end{array}$ & $<0.001$ \\
\hline $\begin{array}{l}\text { Chronic kidney } \\
\text { disease }\end{array}$ & $\begin{array}{c}28 / 153 \\
(18.30 \%)\end{array}$ & $\begin{array}{r}1.48 \\
(0.96 \\
2.27)\end{array}$ & 0.079 & $\begin{array}{c}37 / 104 \\
(35.58 \%)\end{array}$ & $\begin{array}{r}1.00 \\
(0.66 \\
1.53)\end{array}$ & 0.998 & $\begin{array}{c}45 / 76 \\
(59.21 \%)\end{array}$ & $\begin{array}{r}1.60 \\
(0.98 \\
2.61)\end{array}$ & 0.061 \\
\hline $\begin{array}{l}\text { Cerebrovascular } \\
\text { disease }\end{array}$ & $\begin{array}{l}125 / 904 \\
(13.83 \%)\end{array}$ & $\begin{array}{c}1.20 \\
(0.97 \\
1.48)\end{array}$ & 0.096 & $\begin{array}{l}217 / 695 \\
(31.22 \%)\end{array}$ & $\begin{array}{c}0.94 \\
(0.78 \\
1.12)\end{array}$ & 0.493 & $\begin{array}{l}259 / 551 \\
(47.01 \%)\end{array}$ & $\begin{array}{r}1.06 \\
(0.88 \\
1.28)\end{array}$ & 0.552 \\
\hline
\end{tabular}

Operation type

\begin{tabular}{|c|c|c|c|c|c|c|c|c|c|}
\hline $\begin{array}{l}\text { Radical resection } \\
\text { without hysterectomy }\end{array}$ & $\begin{array}{c}182 / 3027 \\
(6.01 \%)\end{array}$ & 1 & & $\begin{array}{l}491 / 2528 \\
(19.42 \%)\end{array}$ & 1 & & $\begin{array}{l}606 / 2030 \\
(29.85 \%)\end{array}$ & 1 & \\
\hline $\begin{array}{l}\text { Radical resection } \\
\text { with hysterectomy }\end{array}$ & $\begin{array}{c}831 / 13325 \\
(6.24 \%)\end{array}$ & $\begin{array}{l}0.82 \\
(0.69 \\
0.97)\end{array}$ & 0.023 & $\begin{array}{c}2426 / 10498 \\
(23.11 \%)\end{array}$ & $\begin{array}{r}0.96 \\
(0.86 \\
1.08)\end{array}$ & 0.502 & $\begin{array}{c}2896 / 8182 \\
(35.39 \%)\end{array}$ & $\begin{array}{l}1.00 \\
(0.89 \\
1.12)\end{array}$ & 0.961 \\
\hline $\begin{array}{l}\text { Simple resection } \\
\text { without hysterectomy }\end{array}$ & $\begin{array}{c}275 / 3252 \\
(8.46 \%)\end{array}$ & $\begin{array}{l}1.68 \\
(1.37 \\
2.05)\end{array}$ & $<0.001$ & $\begin{array}{l}590 / 2727 \\
(21.64 \%)\end{array}$ & $\begin{array}{c}1.39 \\
(1.20 \\
1.60)\end{array}$ & $<0.001$ & $\begin{array}{l}614 / 2252 \\
(27.26 \%)\end{array}$ & $\begin{array}{l}1.11 \\
(0.97 \\
1.29)\end{array}$ & 0.139 \\
\hline Simple resection with & $223 / 2223$ & 1.47 & $<0.001$ & $461 / 1867$ & 1.22 & 0.012 & $529 / 1575$ & 1.08 & 0.341 \\
\hline
\end{tabular}




\begin{tabular}{|c|c|c|c|c|c|c|c|c|c|}
\hline hysterectomy & (10.03\%) & $\begin{array}{l}(1.19 \\
1.82)\end{array}$ & & $(24.69 \%)$ & $\begin{array}{l}(1.04, \\
1.42)\end{array}$ & & (33.59\%) & $\begin{array}{l}(0.93 \\
1.25)\end{array}$ & \\
\hline Others & $\begin{array}{l}154 / 1348 \\
(11.42 \%)\end{array}$ & $\begin{array}{r}1.84 \\
(1.46 \\
2.32)\end{array}$ & $<0.001$ & $\begin{array}{l}362 / 1170 \\
(30.94 \%)\end{array}$ & $\begin{array}{c}1.64 \\
(1.38, \\
1.93)\end{array}$ & $<0.001$ & $\begin{array}{l}449 / 984 \\
(45.63 \%)\end{array}$ & $\begin{array}{r}1.75 \\
(1.48 \\
2.08)\end{array}$ & $<0.001$ \\
\hline \multicolumn{10}{|l|}{$\begin{array}{l}\text { Neoadjuvant } \\
\text { chemotherapy }\end{array}$} \\
\hline No & $\begin{array}{c}725 / 12231 \\
(5.93 \%)\end{array}$ & 1 & & $\begin{array}{c}1966 / 10361 \\
(1.90 \%)\end{array}$ & 1 & & $\begin{array}{c}2437 / 8632 \\
(28.23 \%)\end{array}$ & 1 & \\
\hline Yes & $\begin{array}{c}940 / 10944 \\
(8.59 \%)\end{array}$ & $\begin{array}{r}1.29 \\
(1.16 \\
1.44)\end{array}$ & $<0.001$ & $\begin{array}{c}2364 / 8429 \\
(28.05 \%)\end{array}$ & $\begin{array}{r}1.43 \\
(1.32 \\
1.53)\end{array}$ & $<0.001$ & $\begin{array}{c}2657 / 6391 \\
(41.57 \%)\end{array}$ & $\begin{array}{c}1.50 \\
(1.39 \\
1.61)\end{array}$ & $<0.001$ \\
\hline \multicolumn{10}{|l|}{ Transfusion } \\
\hline No & $\begin{array}{c}416 / 10855 \\
(3.83 \%)\end{array}$ & 1 & & $\begin{array}{c}1173 / 8812 \\
(13.31 \%)\end{array}$ & 1 & & $\begin{array}{c}1461 / 7096 \\
(20.59 \%)\end{array}$ & 1 & \\
\hline Yes & $\begin{array}{c}1249 / 12320 \\
(10.14 \%)\end{array}$ & $\begin{array}{c}2.97 \\
(2.63, \\
3.35)\end{array}$ & $<0.001$ & $\begin{array}{c}3157 / 9978 \\
(31.64 \%)\end{array}$ & $\begin{array}{r}2.96 \\
(2.73, \\
3.20)\end{array}$ & $<0.001$ & $\begin{array}{c}3633 / 7927 \\
(45.83 \%)\end{array}$ & $\begin{array}{c}3.07 \\
(2.84 \\
3.32)\end{array}$ & $<0.001$ \\
\hline \multicolumn{10}{|l|}{ Case volume } \\
\hline $\begin{array}{l}\text { High-volume } \\
\text { (>100 cases/year) }\end{array}$ & $\begin{array}{c}494 / 7896 \\
(6.26 \%)\end{array}$ & 1 & & $\begin{array}{c}1470 / 6154 \\
(23.89 \%)\end{array}$ & 1 & & $\begin{array}{c}1706 / 4694 \\
(36.34 \%)\end{array}$ & 1 & \\
\hline $\begin{array}{l}\text { Medium-volume } \\
\text { (30-100 cases/year) }\end{array}$ & $\begin{array}{c}435 / 6151 \\
(7.07 \%)\end{array}$ & $\begin{array}{c}1.18 \\
(1.02, \\
1.35)\end{array}$ & 0.022 & $\begin{array}{c}1087 / 5108 \\
(21.28 \%)\end{array}$ & $\begin{array}{c}0.92 \\
(0.84 \\
1.01)\end{array}$ & 0.084 & $\begin{array}{c}1317 / 4194 \\
(31.40 \%)\end{array}$ & $\begin{array}{l}0.87 \\
(0.79 \\
0.96)\end{array}$ & 0.004 \\
\hline $\begin{array}{l}\text { Low-volume } \\
\text { (<30 cases/year) }\end{array}$ & $\begin{array}{c}736 / 9128 \\
(8.06 \%)\end{array}$ & $\begin{array}{c}1.28 \\
(1.13 \\
1.45)\end{array}$ & $<0.001$ & $\begin{array}{c}1773 / 7528 \\
(23.55 \%)\end{array}$ & $\begin{array}{r}1.06 \\
(0.97 \\
1.15)\end{array}$ & 0.214 & $\begin{array}{c}2071 / 6135 \\
(33.76 \%)\end{array}$ & $\begin{array}{r}1.02 \\
(0.94 \\
1.12)\end{array}$ & 0.621 \\
\hline
\end{tabular}

$\mathrm{OR}$, odds ratio; $\mathrm{Cl}$, confidence interval 